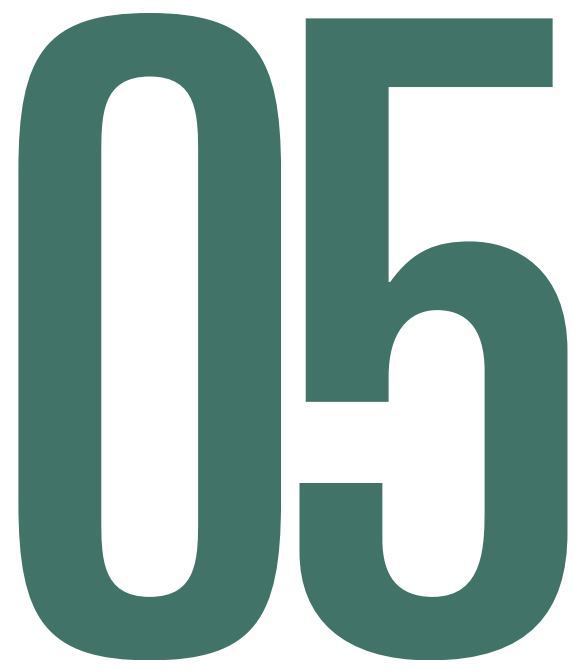

Bases epistemológicas, entre el diseño y la abstracción.

\title{
FUNCIONALIDAD DEL BOCETO EN LA PROYECCIÓN CONCEPTUAL DEL DISEÑO.
}

\author{
María de la Concepción Hurtado Abril \\ Universidad de Sonora \\ marielahurtado@gmail.com \\ Maestría en Administración, Profesor
}

en el Departamento de Arquitectura y Diseño Gráfico de la Universidad de Sonora

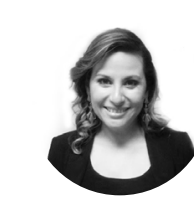

MADGU. Mundo, Arquitectura, Diseño Gráfico y Urbanismo

ISSN: 2594-1208 


\section{Resumen Artículo}

Palabras clave: funcionalidad, boceto, epistemología, abstracción. Keywords: functionality, sketch, epistemology, abtraction

Resumen

Durante mucho tiempo se ha discutido sobre el concepto y utilidad del boceto como un elemento o componente del proceso de diseño. Algunos le consideran necesario e indispensable, otros simplemente lo ignoran. En uno y otro caso, se advierte un desconocimiento sobre su significado $y$ sobre lo que significa como parte del conocimiento y del proceso creativo que el ser humano posee. Conocer qué es y cómo se da, sin abundar en su conocimiento profundo, es de vital importancia, sobre todo para quienes inician su aprendizaje y labor dentro del campo del diseño. La discusión se centra en su origen, cómo se concibe y para qué sirve. Una reflexión sobre lo anterior ayuda a tener una interpretación al alcance de todos y su utilidad.
Abstract

For a long time, the concept and usefulness of the sketch has been discussed as an element or component of the design process. Someones consider it necessary and indispensable, others simply ignore it. In both cases, there is a lack of knowledge about its meaning and what it means as part of the knowledge and creative process that the human being possesses. Knowing what is and how it is given, without abounding in your deep knowledge, is of vital importance, especially for those who begin their learning and work within the field of design. The discussion focuses on its origin, how it is conceived and what it is for. A reflection on the above helps to have an interpretation available to all and its usefulness. 
María de la Concepción Hurtado Abril

\section{Antecedentes}

En las profesiones creativas donde está involucrado el diseño, es ampliamente valorizada la creatividad para la solución de problemas, porque en las universidades se exige a los alumnos que realicen piezas originales. Pero, ¿son los bocetos esenciales para la creación de proyectos conceptuales originales y creativos?, los profesionales consideran que Sí; grandes diseñadores como Meave, Saúl Blass o Paula Sher, utilizan al boceto en la parte crucial de la creación proyectual, pero sin embargo los estudiantes se reúsan a realizarlos, y no es hasta la vida profesional del diseñador, según se evidencia, donde al buscar destacar en el ámbito laboral, se considera iniciar con el boceto. En esta búsqueda, el profesionista para realizar diseños impactantes, se da cuenta que existen pocos libros de diseño que hablan al respecto, aunado a los pocos también, sobre bocetos o bosquejos en el arte y en el diseño industrial o arquitectónico.

La ambigüedad de la propia palabra crea una confusión, y pueden encontrarse diferentes nombres como bocetos, bosquejos, esbozos o dibujos, entre otros, agregando a ello que la definición es escaza e incluso no acorde; en síntesis, diferente.

Rodríguez Aranda (2009), comenta que, a lo largo del tiempo, se han utilizado palabras muy diversas para definir las primeras fases creativas de la obra de arte o del proceso de diseño: apunte, borrón, estudio, garabato, mancha, esquema, nota, croquis, esbozo, etc. con esto, se puede deducir entonces que la palabra boceto es un término que engloba las representaciones del dibujo en su parte inicial. 
Siguiendo a Rodríguez Aranda (2009), se denomina boceto, al objeto de estudio iniciando con su epistemología. La Real Academia Española (2018), señala proveniente del italiano bozzeto y lo define de tres formas distintas: 1 . proyecto o apunte general previo a la ejecución de una obra artística. 2. Esquema o proyecto en que se bosqueja cualquier obra. 3. m. Exposición sucinta de los rasgos principales de algo.

Rodríguez Aranda (2009), por su parte hace un estudio detallado de la definición de bocetos en sus diferentes dimensiones, destacando que proveer un bosquejo es determinar ese conjunto de fenómenos todavía imprecisos en su interior, pero delimitados en su entorno.

Respecto a la tercera definición de Rodríguez Aranda (2009) del bosquejo como parte de este entramado reflexivo, se podría extraer que:

"Su función consiste en desentrañar lo intangible; en comenzar a identificar el precepto, permitiéndonos observar, no obstante, con cierto recelo, aquello que estamos intentando formalizar gráficamente. No tenemos una estructura interior clara de lo imaginado, pero sí deja al descubierto dentro del espacio en el que se circunscribe" (p.86).

Esta dimensión presentada por el autor, plantea cómo el boceto nos ayuda a desentrañar los pensamientos y convertirlos en algo tangible en su forma más primitiva para irla descubriendo poco a poco.

Una definición a partir de la práctica, apoyada en su conocimiento teórico y retomada esta idea de lo intangible en nuestro cerebro, (Dondis, Beramendi y Puente, 2017) reafirma este análisis, en su libro Sintaxis de la imagen, donde dice que toda idea primero es imagen y luego idea, quedando claro que antes que podamos crear se tiene que imaginar.

Chávez et al. (2004, p.40), en su estudio de neurobiología de la creatividad, crean una ruta física de cómo se comportan las ideas en nuestro cerebro, afirmando que, "el índice de creatividad se correl- 
ciona con el flujo cerebral en múltiples áreas de ambos hemisferios cerebrales, las cuales están involucradas en el procesamiento multimodal, en funciones cognitivas complejas y en el procesamiento de emociones"

Si se atiende a lo anterior, puede verse cómo las ideas creativas son complejas y se forman en nuestro cerebro rápidamente; las ideas no son una imagen nítida que podemos imprimir fácilmente sino ambiguas, sin detalle. La famosa frase imagen fotográfica de las ideas no existe, las neuronas se mueven en cuestión de milisegundos. Es aquí cuando la bocetación toma una verdadera relevancia y es necesaria para poder transmitir en papel lo que nuestro cerebro está ideando. Sin embargo, si nos detenemos a pensar detenidamente en la imagen, para después plasmarla ésta se pierde o se generan nuevas ideas diferentes a la primera, resultando collages de ideas, sin forma ni sentido.

Si como se señala que el boceto es tan importante, ¿porque para muchos diseñadores arquitectónicos y gráficos no es objeto de estudio? la hipótesis que se plantea, permite afirmar el boceto, en el caso de los profesores, desconocen su origen y relación con el diseño y simplemente no saben cómo en realidad deben enseñarlo; nadie procura ser guía y advertir de su origen, su relación con el diseño y cómo realizarlo, y desconocen las diferentes técnicas que ayudarán a la exploración y concreción de ideas concretas.

Acudir al significado del boceto y en su conocimiento (epistemología), ayuda a entenderlo mejor y ubicarlo como un elemento situado dentro de nuestras capacidades háptico-cerebrales y como un instrumento que se encuentra entre la abstracción y el diseño.

Iniciar este estudio con la naturaleza misma del boceto, es un propósito de esta reflexión. El problema de diseño siempre es complejo y su objetivo es la creación de todo proyecto; es la puesta en escena de una síntesis visual para la concepción proyectual, en forma eficaz y creativa.

El boceto para el diseñador es la forma de transformar (crear) lo intangible en tangible, expresar una idea u objetos en diferentes formas. Para lograr esto se deben conocer las diferentes formas de 
construcción, dando origen a las formas más primitivas o básicas (el circulo, triangulo, cuadrado o punto), y logrando así una elasticidad y variedad de propuestas en la interpretación misma. Para lograr la idea intangible y convertirla en algo más concreto, se necesita al dibujo rápido en todas sus formas, para convertirlo en el delineamiento, es decir en sus primeras expresiones gráfica y luego convertirlo en proyecto.

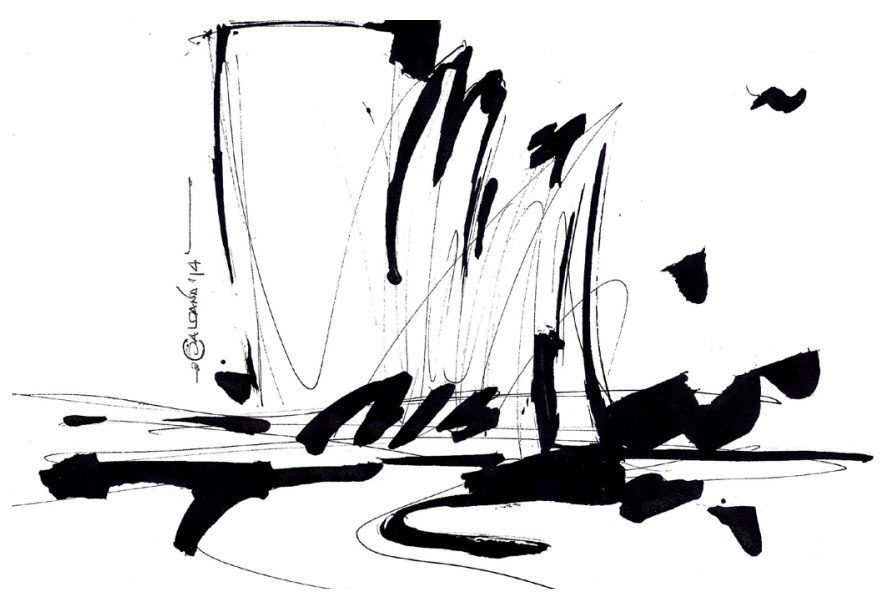

Ilustración 1. Boceto rápido, técnica tinta china para diseño conceptual arquitectónico Autor: Fernando Saldaña Córdova.

En este estudio del boceto se destacan ciertas características esenciales, como la rapidez del dibujo sin esfuerzo, esto para lograr capturar la mayor cantidad de ideas en nuestro cerebro, permitiendo en cuestión de segundos captar las imágenes que se encuentran en lo más profundo de nuestra mente; la rapidez, por tanto, conducirá a obtener una divergencia sustancial y si tomamos en cuenta que cantidad es igual a calidad en la obcecación, nos acercamos cada vez más al objetivo fijado.

El ejercicio del boceto rápido nos permite moldear nuestro cerebro para convertirnos poco a poco en personas creativas y llenas de ideas; nos lleva a ir evolucionando para contar con una apertura de propuestas que nunca habíamos imaginado.

MADGU. Mundo, Arquitectura, Diseño Gráfico y Urbanismo 


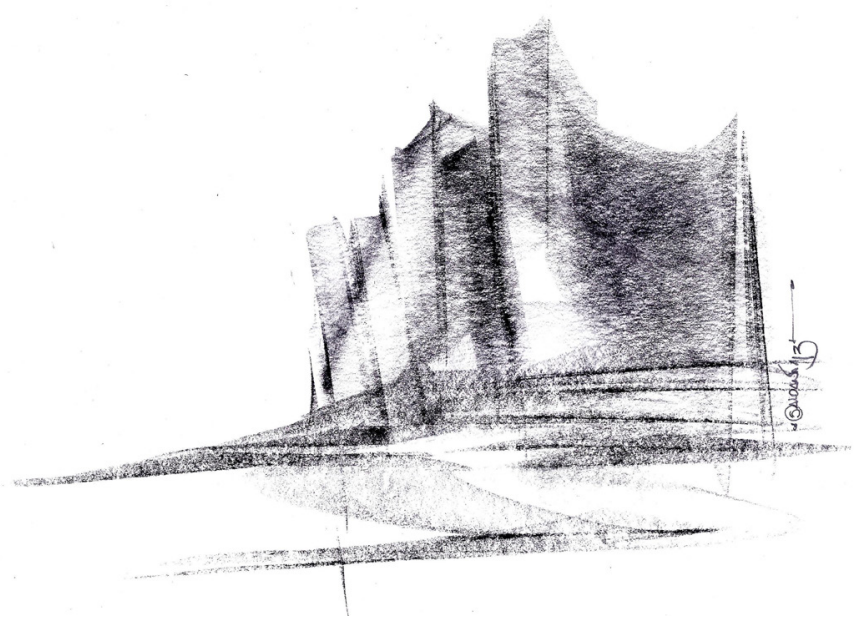

Ilustración 2. Boceto rápido, técnica carbon para diseño conceptual arquitectónico Autor: Fernando Saldaña Cordoba.

La prontitud ayuda a transferir (pasar de un lugar a otro) sin preocupaciones, detalles de nuestras ideas. La preocupación de generar grandes ideas, de realizar algo creativo, es frustrante, agobia al diseñador, hace que el proyecto sea cansado y tedioso, forzar a nuestra mente a crear, lo que no ayuda. Es necesaria la técnica de la despreocupación para poder llegar al objeto de diseño. Este método fue y es utilizado por grandes maestros creativos, como Leonardo Da Vinci o Frank Gehry, con grandes éxitos al nivel creativo. En ellos encontramos constantes sobre el dibujo del boceto el cual debe de ser impreciso y ambiguo, esto para dar pie a nuevas ideas y a las ya existentes.

Si se realizan dibujos muy elaborados, el cerebro se limita para ir desarrollando más ideas. En ese sentido Olaizola Rengifo (2011, p.23), escribe que:

"el dibujo puede estimular el sentido o la dirección del pensamiento. Es decir, el enfrentarse a la necesidad de expresar ideas y conceptos por medio de bocetos o imágenes, lleva al estudiante a ejercitar la observación para sintetizar mucha de la información que recibe; esto le exige verificar continuamente las ideas a partir de las cuales construye sus bocetos." 
Para un diseñador editorial, cartelista, ilustrador o arquitecto, se requiere lograr un nivel de abstracción de ideas, y lograrlo por medio del boceto, les resulta de mucha ayuda. Es entonces donde el papel de boceto toma su importancia revelando a escala las diferentes soluciones gráficas para impulsar la idea gráfica o proyectual.

Por otra parte, si atendemos a la práctica, otras características a destacar sobre el boceto es que tiene que ser a escala, con ambigüedad y síntesis. Saldaña, (2012, p.38) sostiene que "proveer una concepción de la realidad, y expresar una idea con el contraste de líneas gruesas y delgadas, agregando solo manchas, es una manera de usar un método de representación gráfica fácil y rápida". Una exigencia con la que el diseñador tendrá que trabajar intensamente para poder llevar a cabo el ejercicio del boceto. De manera que el dibujo simple y la rapidez de los trazos establece que quien lo efectúa, pueda potenciar lo que existe en la intangibilidad de su mente.

Otra característica esencial del boceto es el tamaño, debe observar que la escala permita la facilidad y rapidez de los trazos al diseñador, recomendándose realizar unos mini bocetos con plumón en donde por medio de una secuencia marcada, vaya desarrollando la idea y refinándola hasta llegar a planteamientos que lo acerque al proyecto definitivo.
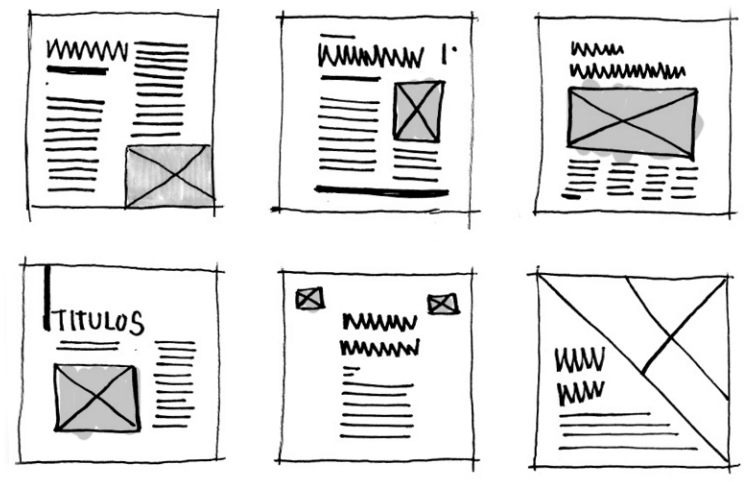

Ilustración 3. Boceto mini para la diagramación editorial de revista Autor: María Hurtado Abril .

MADGU. Mundo, Arquitectura, Diseño Gráfico y Urbanismo 
El boceto debe de ser representativo de lo que se quiere lograr, debe de poseer la sustancia de la solución gráfica; debe procurarse la síntesis visual. Obedecer al tipo de proyecto ya sea editorial, publicitario o de marca, entre otros, es necesario partir de desarrollar y realizar un esquema, el cual deberá guiar a la producción final del mismo. Se debe de conseguir un dibujo abstracto de lo que se busca, que ayudará a encontrar los pros y contras del mismo, que presente y defina las necesidades materiales y de producción, estilo de ilustración, colores, materiales, edición etc. que se ajuste a las necesidades del diseñador.

El ejercicio del boceto debe auxiliar, en lo posible, el área académica y profesional, y ser una herramienta esencial para la vida del creativo. Por tanto, es importante señalar algunas de las técnicas del bosquejo encontradas en el transcurso del tiempo y clasificada según la etapa creativa.

Habrá que decir que el trabajo de bocetar se conoce de diversas maneras; he aquí algunas, entendiendo que se refiere, sobre todo, a las técnicas o modos de plasmar las ideas. Primeramente, encontramos al dibujo espontáneo, definido como la generación desenvuelta de líneas y trazos fluidos para representar ideas o formas concretas. Este tipo de técnica es generada en las primeras etapas del creativo para la exploración y compresión de la forma utilizando línea, punto, forma o mancha entre otras (Saldaña Córdova, 2012), descritas a continuación:

El boceto mini: es la concepción de dibujos en escala muy reducida, el proceso exige abstenerse de añadir detalles. Al ser reducido se puede abordar varias alternativas rápidamente y lograr una secuencia del surgimiento de las ideas. Los expertos sugieren hacerlo con pluma o plumón para evitar borrar y agregar detalles.

El boceto quemado: es regularmente usado en diseño de logotipos o tipografía donde el bosquejo se rellena para hacer un estudio rápido de la contra forma y el uso del espacio en el mismo. 
El boceto de contorno: usado comúnmente en publicidad o cine para recrear una escena velozmente y carente de relleno, utilizando solo contorno eludiendo detalles de retícula y forma. En este tipo de boceto se puede explorar la posición y tamaños del encuadre.

El boceto de experimentación de mancha: son bocetos donde una mancha de tinta o rasgado de papel nos da ideas para la conceptualización gráfica.

\section{Conclusión}

La importancia del boceto recae en ser parte importante para la solución de objetos gráficos innovadores y no solo en clonar o copiar ideas de otros, sin ser realmente la solución para el problema.

No puede negarse que grandes propuestas de arte, arquitectónicas o de diseño en general, por tener el proceso de bocetaje en su desarrollo proyecual, son hoy obras que maravillan y que, observando su proceso, el boceto aparece como el eje central de dichas creaciones.

Los grandes diseñadores lo aconsejaron y lo practicaron, y hoy en día muchos de ellos lo practican como base de su trabajo. Es para ellos una herramienta, no solo de expresión sino también de análisis. Véase, si acaso se duda, la obra de quienes son considerados líderes.

\section{Referencias}

Chávez, R., Graff Guerrero, A., García Reyna, J., Vaugier, V. y Cruz Fuentes, C. (2004). Neurobiología de la creatividad: resultados preliminares de un estudio de activación cerebral. Salud Mental, 27 (3), 38-46.

Dondis, D., Beramendi, J. y Puente, M. (2017). La sintaxis de la imagen. Barcelona: Gustavo Gili.

Olaizola Rengifo, C. (2007). Aprendiendo a pensar, dibujando. Theoria, 16 (1), 23-30.

MADGU. Mundo, Arquitectura, Diseño Gráfico y Urbanismo 
Real Academia Española (2018). Diccionario de la Real Academia de la Lengua Española. Recuperado de http://www.rae.es/

Rodríguez Aranda, S. (2009). El boceto entre el diseño y la abstracción Discrepancias y concordancias en la interpretación gráficos-plástica de la idea. (Tesis Doctoral). Universidad de Granada, Granada, España.

Saldaña Córdova, F. (2012). La tecnología vs las habilidades innatas que él está dejando de usar el hombre en su vida diaria. En Maciel Carbajal, C. (Ed.) La representación gráfica más que una herramienta de comunicación (pp.33-46) Guadalajara: Universidad de Guadalajara. 